Res Publica. Revista de Historia de las Ideas Políticas ISSN: 1576-4184

http://dx.doi.org/10.5209/RPUB.54896

\title{
Maquiavelo y Moisés
}

\author{
Miguel Á. Granada*
}

Recibido: 15 de febrero de 2016 /Aceptado: 21 de octubre de 2016

Resumen. El presente artículo estudia el juicio de Maquiavelo sobre Moisés, atendiendo fundamentalmente a las menciones del profeta en El Príncipe y los Discorsi. Maquiavelo interpreta a Moisés, a partir de los paralelismos con otros fundadores de estados que permiten atribuir las características del uno a los otros y viceversa, como un príncipe nuevo cuya iniciativa religiosa tiene una función política y que actúa sobre el cuerpo social a partir del imperativo de la necessità. Nuestro estudio considera también las diferencias entre la correcta acción política de Moisés (profeta armado que recurre a la violencia obligado por la necesidad) y las limitaciones y defectos de la acción política de los dos líderes florentinos Savonarola y Piero Soderini.

Palabras clave: Moisés; legislador y Dios; príncipe nuevo; Savonarola; Piero Soderini; profeta armado.

\section{[en] Machiavelli and Moses}

Abstract. The present essay studies Machiavelli's assessment of Moses as it emerges from The Prince and Discourses on Livy. In these works Machiavelli interprets the role of the Biblical leader starting from the analogy between Moses and other founder of states. In this light Moses is interpreted as a new prince who acts on the social body out of the imperative of political necessity, and whose religious initiative has a political function. In addition, the essay considers the differences between the rightful political action of Moses (an armed prophet turning to violence out of necessity) and the limitations and shortcomings of the political actions of the two Florentine leaders Girolamo Savonarola and Piero Soderini.

Keywords: Moses; lawgivers and God; new prince; Savonarola; Piero Soderini; armed prophet.

[Moise] andò lui solo nel monte per non aver testimonii, e quelle nubi che si vedevano erano causate da suffumigii o da spiriti ignei, e la legge da lui data era da lui finta e non data da Dio, perché era una legge tirannica e sanguinolenta.

L. Firpo, Il processo di Giordano Bruno, p. 274.

Se ha dicho, y no una sola vez, que la carta más famosa de la literatura italiana la ha escrito Nicolás Maquiavelo. Se trata de aquella del 10 de diciembre de 1513 (hace casi 500 años) dirigida desde Florencia a Francesco Vettori, embajador florentino ante la Santa Sede. Con ella Maquiavelo rompía su silencio de varios meses, reanudaba la correspondencia interrumpida desde agosto, interrumpida porque el embajador no había respondido a la carta de Maquiavelo del día 26 de ese mes y el "quondam Secretarius" tampoco había hecho ningún esfuerzo por mantenerla activa. Maquiavelo reanudaba la correspondencia respondiendo a la carta que, finalmente,

\footnotetext{
* Universitat de Barcelona granada@ub.edu
} 
Vettori había escrito desde Roma el 23 de noviembre y en la que el embajador había justificado su silencio precedente diciendo:

No os respondí entonces porque temía que nos ocurriera a vos y a mí como nos ha ocurrido en alguna ocasión a mí y al Panzano, que habíamos empezado a jugar con cartas viejas y malas y enviado a buscar otras nuevas; y cuando el enviado volvió con ellas, a uno de nosotros dos nos faltaban los dineros. De la misma manera, nosotros hablábamos de poner de acuerdo a los príncipes y ellos no paraban de jugar, de forma que temí que, mientras nosotros gastábamos las cartas en ponerlos de acuerdo, a alguno de ellos le faltaran los dineros. Desde que interrumpimos la correspondencia se ha visto alguna cosa y, aunque la fiesta aún no ha terminado, creo que es conveniente no hablar de ella hasta que llegue el final ${ }^{1}$.

Respondiendo a esta carta el 10 de diciembre Maquiavelo informaba a su corresponsal y amigo de la actividad a que se había entregado en esos meses anteriores de silencio: horas de mañana y tarde entregadas al ocio literario y al embrutecimiento del juego en la taberna con aldeanos. He aquí sus palabras:

No puedo [...] deciros otra cosa en esta carta que la vida que llevo y si vos estimáis que es posible cambiarla por la vuestra, lo haré de buen grado. Estoy en mi casa de campo, y desde que ocurrieron aquellas últimas desgracias no he estado, en total, ni veinte días en Florencia. Hasta ahora me he dedicado a cazar tordos con la mano. Me levantaba antes del amanecer, preparaba la liga y salía con un montón de jaulas encima [...]; cazaba al menos dos y no más de seis tordos. Así estuve todo septiembre; después, este pasatiempo, aunque ejercitado por despecho y extraño a mis gustos, ha venido también a faltarme para mayor contrariedad. Cuál es mi vida ahora, os lo voy a decir: me levanto por la mañana con el sol y me voy a un bosque de mi propiedad que estoy haciendo talar; estoy allí dos horas examinando el trabajo del día anterior y pasando un rato con aquellos leñadores, que siempre tienen algún pleito entre manos o entre sí o con los vecinos. [...] Una vez me he ido del bosque me acerco a una fuente y desde allí al lugar donde tengo dispuestas las redes para capturar los pájaros. Llevo un libro conmigo, o Dante o Petrarca o alguno de esos poetas menores, como Tíbulo, Ovidio y otros semejantes: leo sus pasiones amorosas y sus amores, me acuerdo de los míos y gozo un buen rato con esos pensamientos. Después me traslado siguiendo el camino hasta la hostería, hablo con los que pasan, les pregunto por noticias de sus lugares de origen, me entero de diversas cosas y tomo nota de los gustos variados y de la diferente fantasía de los hombres. Llega entretanto la hora de comer y con mi familia me alimento con lo que esta pobre villa y este pequeñísimo patrimonio permiten. Después de comer vuelvo a la hostería: allí está el posadero y, por lo general, un carnicero, un molinero, dos panaderos. Con ellos me envilezco todo lo que queda del día jugando a las car-

\footnotetext{
En N. Maquiavelo, Antología, edición de M. A. Granada, Barcelona, Península, 2009³ para un estudio reciente sobre la transmisión y el texto de esta carta con discusión de algunos de los problemas que plantea, véase W. J. Connell, "New light on Machiavelli's letter to Vettori, 10 December 1513", en Europa e Italia. Studi in onore di Giorgio Chittolini. Europa and Italy. Studies in honour of Giorgio Chittolini, Florencia, Firenze University Press, 2011, pp. 93-127.
} 
tas y a los dados, de donde nacen mil disputas e infinitos insultos con palabras injuriosas, y las más de las veces se lucha por un cuarto y se nos oye, sin embargo, gritar desde San Casciano. Envuelto así entre estos miserables, saco de mi cabeza todo resto de orgullo y me desahogo de la malignidad de esta suerte mía, contento de que me arrastre por esta vía, a ver si se avergüenza de una vez ${ }^{2}$.

Son horas seguidas, sin embargo, de otras varias horas nocturnas de meditación política sobre los clásicos:

Llegada la noche, me vuelvo a casa y entro en mi escritorio; en el umbral me quito la ropa de cada día, llena de barro y de lodo, y me pongo paños reales y curiales. Vestido decentemente, entro en las antiguas cortes de los antiguos hombres, donde - recibido por ellos amistosamente - me nutro con aquel alimento que es mi único alimento y para el cual nací: no me avergüenzo de hablar con ellos y de preguntarles por la razón de sus acciones, y ellos con su humanidad me responden; durante cuatro horas no siento pesar alguno, me olvido de toda preocupación, no temo la pobreza, no me da miedo la muerte: me transfiero enteramente en ellos. Y como Dante dice que no hay ciencia si no se retiene lo que se ha aprendido, yo he tomado nota de aquello de lo que en mi conversación con ellos he hecho capital y he redactado un opúsculo De principatibus ${ }^{3}$, donde profundizo en la medida de mis posibilidades en las particularidades de este tema, discutiendo qué es un principado, cuántas son sus clases, cómo se adquieren, cómo se gobiernan, por qué se pierden. Y si alguna vez os ha agradado alguna fantasía mía, ésta no debería disgustaros y a un príncipe, especialmente a un principe nuevo, debería serle grata; por eso lo dirijo al magnífico Giuliano [de Médici]. Filippo Casavecchia lo ha visto; él os podrá informar con más detalle de la obra en sí y de los razonamientos que hemos tenido al respecto, aunque todavía sigo engordándolo y puliéndolo 4 .

El Príncipe, pues, ha nacido. No voy a entrar en la cuestión de si - como han pretendido Federico Chabod, Roberto Ridolfi y Gennaro Sasso, imponiéndolo como doctrina establecida hasta fecha reciente - es todo El Príncipe lo que Maquiavelo ha escrito, consistiendo el "engorde" y el "pulido" únicamente en algunos añadidos y ornamentos estilísticos a un edificio ya construido en su totalidad ${ }^{5}$, o bien, como sostuvo inicialmente Friedrich Meinecke y en los últimos años ha revigorizado con nuevos argumentos y datos Mario Martelli, la redacción se prolonga algunos años más allá de $1513^{6}$, pues no hay que olvidar que la primera edición apareció póstuma

\footnotetext{
Ibidem, pp. 394-396.
}

Título confirmado por la tradición manuscrita. El título en vulgar, con el énfasis en el príncipe, procede de la edición romana de 1532 .

4 Maquiavelo, op. cit., pp. 396 ss. Hemos modificado ligeramente la traducción. Para un estudio en profundidad de esta carta remitimos a J. Najemy, Between Friends: Discourses on Power and Desire in the MachiavelliVettori letters of 1513-1515, Princeton, Princeton University Press, 1993, pp. 215-240.

5 Véase F. Chabod, "Sulla composizione de Il Principe di Niccolò Machiavelli” (1927), en sus Scritti su Machiavelli, Turín, Einaudi, 19644, pp. 137-193; R. Ridolfi, Vita di Niccolò Machiavelli, Florencia, Sansoni, $1978^{7}$, p. 237; G. Sasso, Niccolò Machiavelli. Storia del suo pensiero politico, Bolonia, Il mulino, 1980², p. 329.

6 Sobre la tesis de Meinecke véase el artículo de Chabod recogido en la nota precedente. Sobre la reapertura del dossier por parte de Mario Martelli, véase su Saggio sul "Principe”, Roma, Salerno, 1999; véase por último la reformulación de la tesis clásica (Chabod-Sasso) con un ligero desplazamiento en la forma de dos fases de redacción, la segunda hasta mayo de 1514, en G. Sasso, «Il Principe ebbe due redazioni?», en Machiavelli e 
en 1532 en Roma. Mi interés aquí se dirige a otra cuestión: la lectura maquiaveliana de la Biblia, en concreto del Antiguo Testamento, y sobre todo su interés e interpretación de la figura de Moisés, tal como se puede inferir de la obra que aquí nos convoca en su quinto centenario (El Príncipe) y de pasajes de los Discorsi que pueden ayudarnos a entender mejor los pasajes de El Príncipe relativos a Moisés.

Sin embargo, antes de abordar el tema quiero registrar el hecho de que Maquiavelo había escrito El Príncipe, en estos momentos en que los Médici habían recuperado el poder en la república florentina y parecían haber alcanzado la cúspide con la elección de Giovanni de Médici como papa León X, pensando en destinarlo y dirigirlo a la familia imperante. Es verdad que los Médici eran los causantes, en buena medida, de la ruina personal y profesional de Maquiavelo, que había sido depuesto de sus cargos en la cancillería florentina como consecuencia del regreso de la familia tras la caída de la república regida por el gonfaloniero vitalicio Piero Soderini a finales de 1512. Pero también es cierto que los nuevos señores eran los únicos que podían ofrecer al "quondam Secretarius" un empleo consonante con su ejercicio anterior. Maquiavelo lo había dejado claro en su carta de diciembre a Vettori, en quien por otra parte confiaba como posible mediador favorable ante los Médici por su vinculación aristocrática y el favor de que parecía gozar. Maquiavelo decía en la carta que pensaba dirigir el opúsculo a Giuliano de Médici, hermano del nuevo papa, cuyo nombre circulaba como posible "príncipe nuevo" en un estado nuevo gestado desde la Iglesia. Y Maquiavelo concluía con estas palabras:

He discutido con Filippo [Casavecchia] si era conveniente presentar o no este opúsculo mío y, en el caso de que lo fuera, si era conveniente que lo llevara yo personalmente o que lo enviase allí. El no presentarlo me hacía temer que Giuliano ni siquiera lo leyera [...]. Me hacía presentarlo la necesidad que me abruma, porque yo me consumo y no puedo continuar así mucho tiempo sin que la pobreza me haga digno de desprecio, y además el deseo que tendría de que estos señores Médici comenzaran a servirse de mí, aunque debieran comenzar por hacerme dar vueltas a una piedra, porque si después yo no me los ganaba me compadecería de mí mismo. Por eso, si se leyera mi obra, se vería que los quince años que he pasado entregado al arte del Estado no los he ni dormido ni jugado, y todo el mundo debería valorar el servirse de alguien cargado de experiencia a cuenta de otros. De mi lealtad no debería haber duda alguna, porque habiendo observado siempre la palabra no voy ahora a aprender a romperla, y quien se ha mantenido fiel y bueno

\footnotetext{
gli antichi e altri saggi, II, Milán-Nápoles, Ricciardi, 1988, pp. 97-276; también Sasso, Niccolò Machiavelli. I. Il pensiero politico, Bolonia, Il Mulino, 1993, pp. 349 s., y G. Inglese, "Introduzione”, en N. Machiavelli, Il Principe, ed. de G. Inglese, Turín, Einaudi, 1995, pp. V-XI. Para la cronología "larga", hasta 1518, véase la presentación del problema en la reciente edición de Martelli en N. Machiavelli, Il Principe, a cura di M. Martelli, en Edizione Nazionale delle Opere, I/1, Roma, Salerno editrice, 2006, pp. 9-49, 427-486. Recogemos, sin embargo, la opinión de un intérprete tan acreditado como E. Cutinelli-Rèndina, Introduzione a Machiavelli, Roma-Bari, Laterza, $2003^{5}$, p. 27 , a quien "non sembra che vi siano ragioni sostanziali, allo stato attuale della documentazione, per allontanarsi da quella che fu la tesi di Chabod". Más recientemente, Paul Larivaille ha terciado en la discusión proponiendo 1516 como fecha de la última intervención de Maquiavelo en el capítulo XXVI y por tanto de la conclusión del opúsculo: véase P. Larivaille, "In attesa della stele di Rosetta. Appunti sulla cronistoria di un rompicapo machiavelliano", Filologia e critica, 2, 2009, pp. 261- 288, especialmente 276 ss; y aún más recientemente, Connell, op. cit., pp. 94, 103, 121 s., ha argumentado, a partir de algunos pasajes en la carta del 10 de diciembre de 1513, que en esa fecha Maquiavelo había escrito también los capítulos XVXIX y XXV, e incluso que "the work was substantially complete through chapter 25 by December 1513 ".
} 
durante cuarenta y tres años, que son los que yo tengo, no debe poder cambiar de naturaleza; y de la lealtad y bondad mía testimonia mi pobreza ${ }^{7}$.

Ahora bien, no se trataba de un mero ejercicio de oportunismo personal y "cambio de chaqueta". Maquiavelo ofrecía su "saber político", que estimaba útil a los nuevos señores de Florencia, en un momento en que el definitivo asentamiento constitucional del Estado florentino estaba por decidir. Ese saber político aparecía formulado en El Príncipe y también se había manifestado en la discusión de la convulsa política italiana y europea llevada a cabo en la correspondencia con Vettori ("ma il destinatario ideale era il papa") ${ }^{8}$ entre marzo y agosto de 1513 y en la parte de los Discorsi redactada hasta el momento ${ }^{9}$. Digamos, en síntesis, que, según Maquiavelo, el interés de los Médici se unía al interés general de Florencia y a la conviccion política (republicana) de Maquiavelo, en la dirección de una reforma constitucional que debía implantar un principado nuevo, un principado civil basado en una alianza del príncipe Médici con el umore popolare en dirección antioptimate ${ }^{10}$. Dicho esto, véamos cómo entra Moisés en el planteamiento expuesto por Maquiavelo en El Príncipe.

\section{Moisés en El Príncipe y los Discorsi}

Según el estudioso norteamericano Werner Gundersheimer, entre las lecturas nocturnas de Maquiavelo en el verano y otoño de 1513 figuraba el Antiguo Testamento; y todavía más: "One of the heroes about whom Machiavelli was thinking in 1513, and on whom he seems to have patterned his prince, was Moses" ${ }^{11}$. Aun reconociendo los problemas que pueden derivarse de la redacción ampliada de la obra y de la dificultad, si no imposibilidad, de determinar cuál fue la redacción llevada a cabo antes de diciembre de 1513, vamos a examinar cuál es el papel y la presencia de Moisés en el texto llegado hasta nosotros a partir de la publicación en 1532.

La primera (y única) mención explícita de Moisés acompañada de un cierto desarrollo aparece en el capítulo VI, donde Maquiavelo presenta la figura decisiva del "príncipe nuevo" o más precisamente donde se ocupa de "los principados completamente nuevos, tanto por su príncipe como por su organización política"12.

\footnotetext{
Antologia, op. cit., pp. 397 ss.
}

Inglese, Introduzione, op. cit., p. VI.

9 Tradicionalmente, desde el ya mencionado artículo de Chabod de 1927, se había aceptado que Maquiavelo había empezado los Discorsi sobre Tito Livio tras la caída de la República soderiniana y su infortunio personal, llegando a los capítulos xvii y xviii del primer libro por las mismas fechas en que la correspondencia con Vettori alcanzaba su punto culminante en julio-agosto de 1513. De hecho, en las reflexiones sobre la posibilidad de reformar una república corrompida en el capítulo xviii (cosa que Maquiavelo ve únicamente mediante la "reducción antes a un Estado monárquico que a uno popular") se vió el momento de máxima tensión teórica que llevó a Maquiavelo a deplegar su teoría del "príncipe nuevo" y muy especialmente del "principado civil", que constituye, según Sasso "el espíritu” de la obra; Véase Sasso, Niccolò Machiavelli. I. Il pensiero politico, cit. p. 384; para una exposición de la problemática actual sobre la cronología de los Discorsi véase F. Bausi, Machiavelli, Roma, Salerno editrice, 2005, pp. 163-181.

10 De hecho esta es la tesis que Maquiavelo sostuvo ya en noviembre de 1512 en el escrito titulado "A los partidarios de los Médici. Tomad buena nota de este escrito" (Maquiavelo, Antología, cit., pp. 314-316).

11 W. Gundersheimer, "San Casciano 1513: A Machiavellian Moment Reconsidered", Journal of Medieval and Renaissance Studies, 17, 1987, pp. 41-58, aquí p. 44.

12 N. Maquiavelo El Príncipe, trad. de M. A. Granada, Madrid, Alianza, 1981, p. 47. 
Es sabido que el capítulo se abre con un exordio retórico de altura, en el que Maquiavelo expone, con poderosas imágenes, el principio de la imitación de modelos excelsos y, por consiguiente, propone al nuevo príncipe mediceo la imitación de grandes fundadores de Estados, con Moisés a la cabeza: "Pasando ya a aquellos que llegaron a ser príncipes por su propia virtud y no por fortuna, afirmo que los más notables son Moisés, Ciro, Rómulo, Teseo y semejantes"13. Es verdad que con un lenguaje cuanto menos ambiguo Maquiavelo acepta que "sobre Moisés no es lícito razonar por haber sido mero ejecutor de las órdenes de Dios", si bien "debe ser admirado aunque sólo sea por aquella gracia que lo hacía digno de hablar con Dios". Sin embargo, como de Ciro y demás príncipes nuevos virtuosos se puede decir que "sus acciones y las instituciones creadas por cada uno de ellos [...] no son diferentes de las de un Moisés que tuvo tan alto preceptor" ${ }^{14}$, resulta lógicamente que Moisés ha sido como los demás y por tanto el comportamiento de los demás nos permite comprender el de Moisés y viceversa. En suma, el comportamiento religioso de Moisés nos permite comprender el de los restantes príncipes nuevos (o debe ser interpretado en su dimensión y funcionalidad política) y el ejercicio político de los otros príncipes nuevos nos da también la clave para interpretar el comportamiento de Moisés ante el pueblo de Israel salido de Egipto ${ }^{15}$. Maquiavelo no ve, pues, a Moisés tanto como el fundador de una religión, desvinculado de la política y con una perspectiva ultramundana, sino como el fundador de un Estado: un legis-lator. Y en esta dimensión política de Moisés la religión por él estableci$\mathrm{da}$, a partir de "aquella gracia que lo hacía digno de hablar con Dios"16, parece ser un instrumento o componente del Estado. Lo mismo ocurre con la función de la religión en los otros estados nuevos creados por otros príncipes nuevos, cuyas "acciones e instituciones (ordini, y la religión es un ordine) no son diferentes de las de un Moisés, que tuvo tan alto preceptor", lo cual permite inferir que también Dios fue un preceptor (real o fingido) de los otros príncipes nuevos con los que el profe-

$13 \quad$ Ibidem, p. 48.

14 Ibidem, p. 47; cfr. J.-L.Fournel-J.-C. Zancarini, "Le Savonarole de Machiavel: Une lecture laïque et politique", Bruniana \& Campanelliana, XX (2014), pp. 47-60, aquí p. 52.

15 Creemos que la ecuación que Maquiavelo establece nos impone interpretar a Moisés a la luz de los demás fundadores de estados y religiones y no lo contrario. Estimamos por ello que es de todo punto erróneo el principio, adoptado por de S. De Grazia, Machiavelli in Hell, Princeton, Princeton University Press, 1989 (tr. it., Machiavelli all'inferno, Roma-Bari, Laterza, 1990, de la que se cita) y en su estela por C. J. Nederman, "Amazing Grace: Fortune, God, and Free Will in Machiavelli's Thought", Journal of the History of Ideas, 60, 1999, pp. 617-638, de leer las declaraciones de Maquiavelo sobre Moisés en su pura literalidad, como expresiones de una sincera posición cristiana que asume sin ningún resquicio de duda la elección de Moisés por el Dios personal, trascendente y providente del cristianismo, que lo habría convertido en su amigo y enviado ante Israel. La decisiva presencia de Moisés en Maquiavelo (con la tendencia añadida a interpretar en parte esa presencia de acuerdo con De Grazia) ha sido también sólidamente argumentada por A. Melamed, The Philosopher-King in Medieval and Renaissance Jewish Thought, Albany, State University of New York Press, 2003, pp. 150-66.

16 Obviamente Maquiavelo se inspira en Éxodo 33, 17: "Dijo Yavé a Moisés: "También a eso que me pides accedo, pues has hallado gracia a mis ojos"; este es el principio inspirador de la interpretación cristiana de Maquiavelo y de su evaluación de Moisés en De Grazia, op. cit., p. 65 y en Nederman, op. cit., p. 620 ss., 629-633. Sin embargo, hemos de tener presente que el término "Grazia (divina)" no es un concepto teórico en Maquiavelo. Por otra parte, la excepcionalidad de Moisés (de acuerdo con la fe judeocristiana) había sido enfatizada por la fuente textual quizá más importante de Maquiavelo, el De legibus et iudiciis dialogus de Bartolomeo Scala (véase la siguiente nota), donde se dice: "Nos Moysem quem, cum Deo fertur locutus, ut amicus ad amicum solet, tabulas dictante Domino quas scripsisset postquam cum eo quadraginta dies totidemque fuisset noctes, quibus quidem nec panem gustavisset aut aquam, tradidisse hominibus primum leges pie credimus" (en Essays and Dialogues, texto latino y trad. de R. N. Watkins, Cambridge (Mass.), Harvard University Press, 2008, § 43, p. 204). 
ta de Israel es puesto en pie de igualdad. En esta evaluación de Moisés Maquiavelo sigue a aquellos autores antiguos que veían la religión como un instrumento y vínculo político y a aquella tradición filosófica (señaladamente el averroísmo) que reconocía en la religión una ley (lex) y en sus fundadores (Moisés, Mahoma, Cristo) profetas que, imponiéndose como enviados e instrumentos de Dios, establecían una comunidad política articulada por la Ley religiosa ${ }^{17}$. Precisamente, en torno al mismo tiempo aproximadamente en que Maquiavelo redactaba El Príncipe Pietro Pomponazzi, filósofo de profesión en la universidad de Bolonia, escribía y publicaba el Tratado sobre la inmortalidad del alma, en el que el político, como "médico de almas" cuyo fin es la salud del cuerpo social mediante la virtud (no mediante la sabiduría), "inventa fábulas para enderezar las ciudades. Sin embargo, en estas fábulas, como dice Averroes [...] ni hay verdad ni hay falsedad propiamente"18.

$\mathrm{Si}$, de acuerdo con la ecuación inicial en Príncipe VI, Moisés es un príncipe nuevo, la necesidad estructural presente en los otros príncipes nuevos podemos aplicarla

17 Independientemente de los autores antiguos y de la tradición averroísta, Maquiavelo pudo encontrar más directamente la apelación a la divinidad por parte de los legisladores en humanistas florentinos del siglo XV como Cristóforo Landino o Poggio Bracciolini y con mucha más probabilidad en el diálogo De legibus de Bartolomeo Scala, humanista florentino y secretario de la cancillería de la república desde 1465 hasta su muerte. En esta obra, redactada en 1483, figura como uno de los interlocutores Bernardo Machiavelli (padre de Nicolás y amigo de Scala) y Scala recoge (poniéndolo, igual que el pasaje citado en la nota precedente, en boca del padre de Maquiavelo) el recurso a la divinidad respectiva por parte de Zoroastro, Carondas, Trismegisto, Licurgo, Dracón y Solón, Numa, Zalmoxis y Mahoma: véase De legibus et iudiciis dialogus, en Scala, op. cit, § 49, p. 210 : "Satis enim modo videtur, sive id ab Iove, sive ab alio quovis deorum id sit, legum primordia a divinitate esse profecta ostendere [legislatores]. Quod et earum autores vario modo apud diversos comprobaverunt, nonmodo quia sic putaverunt posse populos reddere praeceptis suis obsequentiores auctoritate interposita deorum, verum etiam ut id quod nos supra diximus de vera legum origine his accommodatissime confictis fabulis significarent" (cursiva nuestra). En su lista de legisladores Scala no menciona a Moisés (pero véase el texto citado en la nota anterior donde se refiere que Moisés pudo ser el primer legislador) y aunque parece excluir una ficción engañosa por su parte, creemos importante la afirmación de esta común forma de proceder en los legisladores, a la que Maquiavelo suma el legislador de Israel. Agradecemos a Francesco Bausi el habernos dado noticia (con ocasión de un encuentro maquiaveliano en Barcelona, en diciembre de 2013) de este importante pasaje de Scala, cuya letra anticipa la de Discorsi, I, 11: véase ahora F. Bausi, "Da Bernardo a Niccolò Machiavelli: Sui legislatori antichi che fecero ricorso alla religione (Discorsi I 11)", Bruniana \& Campanelliana, XX, 2014 , pp. 25-33; por nuestra parte pensamos que el hecho de que la fuente más probable de Maquiavelo pueda haber sido Scala y humanistas florentinos anteriores no implica que Maquiavelo no haya ido más allá que esas fuentes en la interpretación y elaboración conceptual. Es cierto que, como dice Bausi 2014: 32, «bisogna guardarsi, come scrisse Mario Martelli, dall'incorrere nel grossolano errore di chi "non riesce a distinguere tra Machiavelli e Voltaire" [cf. Mario Martelli, «Machiavelli e Savonarola: valutazione politica e valutazione religiosa», en Martelli 2009: 239-277: 255]", pero es cierto también que es el mismo Martelli quien en ese mismo artículo dice poco más adelante que "in questa compagnia -quella di Numa, di Licurgo, di Solone e, dovremo aggiungere, di Mosè, compreso certamente da Machiavelli tra quei molti altri [aludidos en Discorsi, I, 11], da lui lasciati nell'anonimato (così come nel Principe nella compagnia, oltreché, appunto, Mosè, erano ammesi anche un Teseo, un Romolo, un Ciro -, è in questa compagnia di grandi che Machiavelli pensa a Savonarola", Martelli: 256. Príncipes nuevos, por tanto, Moisés y Savonarola, y como todos los demás apelantes también ellos a Dios, sean o no diferentes de los demás en esa apelación, cuestión esta que abordaremos más adelante.

18 P. Pomponazzi, Tratado sobre la inmortalidad del alma, trad. de J. M. García Valverde, Tecnos, Madrid 2010, pp. 41 ss.; la mención inmediatamente anterior (p. 140) de Moisés, junto con Cristo y Mahoma, permite aplicarle esa dimensión de legislador médico del cuerpo social. En el tratado De incantationibus, redactado en 1520 y nunca publicado en vida del autor por motivos de prudencia, la reducción averroísta de la religión a lex recibe una formulación más articulada. Véase P. Pomponazzi, De incantationibus, ed. de V. Perrone Compagni, Florencia, Olschki, 2011, pp. 149 ss.; sobre el paralelismo (no sólo cronológico, sino sobre todo conceptual) en la interpretación del cristianismo por Maquiavelo y Pomponazzi véase M. Á. Granada, Cosmología, religión y politica en el Renacimiento: Ficino, Savonarola Pomponazzi, Maquiavelo, Barcelona, Anthropos, 1988; una interpretación similar se encuentra en A. G. Parel, The Machiavellian Cosmos, New Haven-Londres, Yale University Press, 1992. 
también a Moisés y viceversa, esto es, el comportamiento de uno nos enseña sobre el de los otros. Maquiavelo nos legitima para ello cuando emplea enunciados universales. Así, cuando en Discorsi I, xi nos presenta la introducción de la religión en Roma por Numa (presentado en el I, xi, 1 como completando la ordenación política de Rómulo y por ello cofundador del estado romano), Maquiavelo nos dice, a propósito de todos los príncipes nuevos:

Y verdaderamente, nunca hubo un legislador que diese leyes extraordinarias a un pueblo y no recurriese a Dios, porque de otro modo no serían aceptadas; porque son muchas las cosas buenas que, conocidas por un hombre prudente, no tienen ventajas tan evidentes como para convencer a los demás por sí mismas. Por eso los hombres sabios, queriendo soslayar esta dificultad, recurren a Dios. Así lo hizo Licurgo, así Solón, así muchos otros que han tenido el mismo propósito que ellos ${ }^{19}$.

Por eso Numa "fingió tener familiaridad con una ninfa" 20 , diciendo al pueblo que ella "le aconsejaba todo lo que luego aconsejaba él al pueblo, y todo esto lo hacía porque quería crear instituciones [ordini] nuevas y desusadas en aquella ciudad y temía que su autoridad sola no bastase" ¿21. ¿Hablaba realmente Numa con una ninfa? Maquiavelo dice que eso no importa. Lo importante es que persuadió al pueblo romano de ello y fue creído. ¿Habló realmente Moisés con Dios? ${ }^{22}$. El Príncipe VI, como hemos visto, parece aceptarlo; lo da incluso por hecho, pero eso no es más que la constatación de que consiguió que el pueblo hebreo lo creyera. Como luego teorizará el cap. XVIII, en materia de religión lo importante no es lo que eres, sino lo que parece que eres a los ojos del vulgo, lo que eres creído. Así, Savonarola (que en tantos aspectos, como veremos, se presentaba a los florentinos como "un nuevo Moisés" y aparece en Maquiavelo como una figura paralela en muchos sentidos al profeta fundador del Estado de Israel) consiguió "persuadir de que hablaba con Dios" al pueblo florentino, "al que nadie llamaría ignorante ni rudo". Y añade: "Yo no quiero juzgar si era verdad o no, porque de un hombre de su talla se debe hablar con respeto" (¡y con cuánto más respeto se debe hablar de Moisés!; de ahí el respeto mostrado en Príncipe VI), pero lo importante políticamente es lo que Maquiavelo puede asegurar: "Pero puedo asegurar que fueron infinitos los que lo creyeron, sin haber visto nada extraordinario [ningún milagro] que les hiciera creer en él"'23. Como en Numa, Savonarola y tantos otros, Moisés es un fundador de un estado que recurre a Dios y a la religión pretendidamente dictada por Dios para establecer su orden político y afianzar su autoridad. Lo importante es el efecto conseguido, no la realidad de su pretensión de hablar con Dios, totalmente inverificable, más allá de la confirmación que da su triunfo o el fin conseguido ${ }^{24}$.

19 El príncipe, ed. cit., p. 65.

20 Como indica Bausi, art. cit., p. 29 nota, "che Egeria fosse una ninfa è informazione assente in Livio [I, 19, 4-5]; lo dicono, invece, oltre allo Scala, Plutarco [...] e, fra i moderni, Poggio Bracciolini”. Es un claro indicio de que, con altísima probabilidad, Maquiavelo toma la letra del pasaje de esas fuentes florentinas contemporáneas.

21 Ibidem, p. 65.

22 El Éxodo bíblico recoge 43 conversaciones entre Dios y Moisés, diez de ellas iniciadas por el profeta. Véase K. H. Geerken, "Machiavelli’s Moses and Renaissance Politics”, Journal of the History of Ideas, 60, 1999, pp. 579-595, aquí 580.

23 Discorsi, I, 11, en Maquiavelo, Discursos sobre la primera década de Tito Livio, trad. de Ana Martínez Arancón, Madrid, Alianza, 1987, p. 66 ss. (hemos modificado la traducción).

24 Cf. Fournel-Zancarini, art. cit., p. 56: "La question de la vérité prophétique n'intéresse pas Machiavel". Pero 
Por otra parte, es necesario e inevitable en el momento fundacional de su estado que el príncipe nuevo recurra a la violencia, incluso a la violencia armada. En suma, se trata - como dice El Príncipe VI para poder predecir su suerte - de saber si «el profeta está armado o desarmado ${ }^{25}$. Y añade que "Moisés, Ciro, Teseo y Rómulo no hubieran podido hacer observar a sus pueblos durante mucho tiempo sus instituciones [ordini] de haber estado desarmados"26, presuponiendo, por tanto, que Moisés ejerció esa violencia armada.

Desarrollando este tema en la tercera parte del tratado, en el capítulo XVII, el príncipe nuevo César Borgia es aducido como ejemplo del buen uso (políticamente constructivo) de la violencia (crueldad). Con ello César Borgia no hizo sino aplicar una ley universal del principado nuevo: "Y de entre todos los príncipes, al príncipe nuevo [a todo príncipe nuevo] le resulta imposible evitar la fama de cruel por estar los Estados nuevos llenos de peligros" y añade la autoridad del poeta romano Virgilio: "La dura necesidad y la novedad del reino me obligan a adoptar tales medidas"27. Según la ecuación Moisés-Príncipe nuevo, el profeta fundador del estado hebreo tuvo que hacer lo mismo. Esto, ciertamente, ya lo ha adelantado el capítulo VI, pero encontramos la exposición más completa y por así decir despiadada en el capítulo xxx del tercer libro de los Discorsi, en un comentario que merece ser analizado cuidadosamente, tanto en lo que nos dice de Moisés como en las comparaciones que introduce con la política contemporánea de Florencia y con sus dos últimos "dirigentes" (en cierto modo príncipes nuevos fracasados): Savonarola y el gonfaloniero vitalicio Piero Soderini, a quien Maquiavelo sirvió durante diez años como secretario de la cancillería y creador de la milizia ciudadana.

"Quien lea inteligentemente [sensatamente] la Biblia - dicen Discorsi III, xxx, 17 - verá que Moisés se vio obligado, si quería que sus leyes y ordenamientos salieran adelante, a matar a infinitos hombres, que se oponían a sus designios movidos sólo por la envidia". Sensatamente o con buen sentido, con discreción, quiere decir no devotamente, sin someter el intelecto en obsequio de la fe (como prescribe en cambio el apóstol en 2 Corintios 10,5). Maquiavelo debe haber pensado en primer lugar en la matanza de "tres mil del pueblo" con ocasión de la primera crisis y cuestionamiento de la autoridad de Moisés en el episodio del becerro de oro. Los levitas fieles a Moisés mataron, siguiendo sus órdenes, a tres mil opositores ${ }^{28}$. Sin embargo en esta ocasión la rebelión es atribuida al "pueblo" en general. Ahora bien, Discorsi III, xxx, atribuye la rebelión a la envidia y ello permite pensar, como ha señalado

\footnotetext{
ya había dicho Mario Martelli, Tra filologia e storia: otto studi su Machiavelli, Roma, Salerno, 2009, p. 254: "L'autenticità della fede del Frate e la sua effettiva religiosità fuoriescono dall'area dell'indagine e, con ogni probabilità, degli interessi machiavelliani. Credo che chiedersi se Savonarola [y en lógica consecuencia también Moisés] credesse veramente in quello che andava predicando, sarebbe stato per Machiavelli, lo stesso che chiedersi se Numa Pompilio parlasse davvero con la ninfa Egeria; né questa mia affermazione dev'essere fraintesa, quasi io intendessi dire che Machiavelli, magari irredendo a coloro che l'affermavano, negasse la verità della rivelazione; credo che negarla gl'interessasse tanto quanto affermarla". Tengamos presente que, como dice Maquiavelo en El Príncipe, cap. XVIII, el triunfo o la consecución del fin lleva al vulgo a pensar que los medios (la autopresentación como enviado de Dios) han sido buenos y verdaderos, "y en el mundo no hay más que vulgo. Los pocos [la minoría clarividente] no tienen sitio cuando la mayoría tiene donde apoyarse". Véase infra, nota 46.

25 El príncipe, op. cit., p. 50.

26 Ibidem; Maquiavelo añade una referencia interesante a la situación del Moisés Savonarola, sobre la que volveremos más adelante.

27 Ibidem., pp. 87-88. Cf. Virgilio, Eneida, I, 562-563: "Res dura, et regni novitas me talia cogunt / moliri".

28 Éxodo 32, 25-29.
} 
John H. Geerken"29, en Salmos 106, 16-18: “Envidiaron a Moisés [...] y se abrió la tierra y se tragó a Datán, y cubrió a los secuaces de Abirón. Y el fuego devoró a su banda". Este pasaje hace, por tanto, efecto de la envidia la rebelión suscitada entre el pueblo por Coré, Datán y Abirón al frente de un contingente de notables, según relata Números 16. Evidentemente, Maquiavelo lee el episodio como una conjura de notables, envidiosos y celosos de la primacía de Moisés, a quien acusan de $\operatorname{tirano}^{30}$ y a quien pretenden reducir a la condición de uno más en medio de la asamblea general: Coré, Datán y Abirón "se alzaron y se pusieron enfrente de Moisés, arrastrando tras sí a doscientos cincuenta varones de los hijos de Israel, todos de los principales de la asamblea, de los del consejo, hombres distinguidos. Se conjuraron contra Moisés y Arón y dijeron a éstos: «Básteos ser uno de tantos, pues santos son todos los de la asamblea, y en medio de todos está Yavé. ¿Con qué derecho os levantáis vosotros sobre la asamblea de Yavé?»" (Éxodo 16: 1-3).

No cabe duda de que la categorización de envidia dada por el salmista permitió a Maquiavelo conectar la rebelión contra Moisés con su propia concepción de uno de los peligros más dramáticos a que se ve enfrentado el príncipe nuevo en su acción renovadora: la oposición de los "pocos", que frente al vulgo "que sólo ve lo que pareces", es decir, lo que aparentas ser, "palpan lo que [realmente] eres" (Príncipe XVIII; ed. cit., p. 92). Estos pocos, los nobles, aristócratas u optimates (el humor de los "grandes"), no pueden soportar, por envidia, la supremacía del nuevo príncipe y suscitan el encono del pueblo, no por amor al pueblo, sino para imponer su propio interés de parte. ${ }^{31}$ Los grandes -dice Maquiavelo en el capítulo IX de El Prínci$p e$, dedicado a esa importantísima variante del principado nuevo que es el llamado "principado civil" - "se creen iguales a él" y por tanto se resisten a que los mande y maneje a su manera ${ }^{32}$. El peligro es tan grande, dice Maquiavelo en el capítulo de Discorsi (III, xxx, 15-16) que hablaba de la envidia contra Moisés y como motivo de su reacción, que "para vencer esta envidia, el único remedio es la muerte de los envidiosos, y si la fortuna es tan propicia al hombre virtuoso que mueren por causas naturales, éste llegará a la gloria sin escándalo [sin violencia homicida]. [...] Pero si no tiene esta suerte, le conviene pensar en el modo de quitárselos de en medio y, antes de hacer nada, conviene que tenga medios para superar esta dificultad"33.

Moisés tenía esos medios, pues ya El Príncipe nos ha dicho en el capítulo VI que era un profeta armado, y los puso en práctica, como testimonia la Biblia a quien la lee sensatamente. Fue, por tanto, un príncipe nuevo a carta cabal. Lo interesante, además, es que, al igual que en ese capítulo de El Príncipe, también Discorsi III, xxx, opone la posición y reacción de Moisés a Savonarola (profeta desarmado y por tanto vencido), pero añade Piero Soderini (el gonfaloniero vitalicio caído en 1512), que está ciertamente ausente de El Príncipe ${ }^{34}$. Por todo ello podemos examinar este

$29 \quad$ Art. cit., p. 589.

30 Números 16, 13: “¿todavía te parece poco habernos sacado de una tierra que mana leche y miel [Egipto], para traernos a morir a un desierto, que también quieres seguir tiranizándonos?”: son palabras de Datán y Abirón.

31 Cf. ya Discorsi, I, viii, 2-3 (ed. cit., p. 53), la referencia, en la Roma republicana, a Manlio Capitolino, que "no podía soportar que se le atribuyese [a Furio Camilo] tanto honor y tanta gloria [...] de modo que, roído por la envidia, [...] se volvió a la plebe, sembrando en ella ideas siniestras".

32 Ed. cit., p. 63.

33 Discursos, ed. cit., p. 383.

34 No era oportuno, ciertamente, que Maquiavelo mentase a Piero Soderini en una obra dirigida a los Médici y encaminada a obtener su favor. Sin embargo, en la medida en que las consideraciones del capítulo XXV sobre la fortuna y la adecuación a la condición de los tiempos recogen los resultados formulados en 1506 en los 
comentario de Discorsi III, xxx, como una continuación ampliada de la oposición entre el príncipe nuevo victorioso Moisés y dos renovadores vencidos y fracasados, por razones diferentes: el fraile Girolamo Savonarola y el gonfaloniero Piero Soderini, ambos en cierto modo príncipes nuevos en la variedad de lo que Maquiavelo denomina, con un hapax con bastantes rasgos de oxímoron, príncipe civil.

Tanto Savonarola como Soderini conocían, según Maquiavelo, esa necesidad de enfrentarse a la envidia optimate. Pero Savonarola "no pudo" oponérsele con el exterminio llevado a cabo por Moisés "por carecer de la autoridad suficiente para poderlo hacer" (su condición de fraile, además de extranjero, le impedía ejercer una magistratura y, además, ejecutar esa violencia armada) ${ }^{35}$ y "porque no fue bien entendido por aquellos de sus seguidores que sí poseían autoridad para ello"36, porque ejercían las magistraturas y estaban en condiciones de ejecutar la acción contra la envidia. No obstante, reconoce Maquiavelo, "hizo lo que pudo [per lui non rimase]", denunciando en sus sermones constantemente a "los envidiosos y a los que se oponían a sus ordenaciones" ${ }^{37}$. Por el contrario, Soderini (que tenía, como jefe de gobierno, autoridad para ejecutar la política que sabía necesaria contra los optimates "envidiosos") no supo llevarla a cabo, optando (erróneamente, en opinión de Maquiavelo) por esperar el beneficio del tiempo, calmar y desmontar la envidia con beneficios a los opositores, confiado en su buena fortuna. Si el juicio en Discorsi sobre el fracaso de Savonarola muestra un notable reconocimiento de la figura del fraile impotente, elevándolo por encima del desprecio mostrado en la famosa carta de marzo de $1498^{38}$, sobre Soderini la actitud de Maquiavelo muestra en cambio la dureza implacable y despectiva frente a la ignorancia y el error:

El otro [Soderini] creía que era posible aplacar la envidia con el tiempo, con bondad, con su fortuna, con beneficiar a alguno; viéndose bastante joven aún y con tantas nuevas simpatías como le granjeaba su modo de proceder, creía poder vencer a todos aquellos que se le enfrentaban por envidia sin ningún escándalo, violencia ni tumulto; y no sabía que no se puede esperar el tiempo, la bondad no basta, la fortuna varía y la maldad no puede aplacarse con regalos. Así que tanto el uno como el otro fracasaron y su fracaso se debió a que no supieron o pudieron vencer a la envidia ${ }^{39}$.

llamados Ghiribizzi al Soderini (véase Maquiavelo, Antología, cit., pp. 253-257; el destinatario era un sobrino del gonfaloniero), con la oposición tácita de la cauta política de éste al ímpetu triunfante del papa Julio II, ello muestra la presencia tácita del gonfaloniero derrotado en El Príncipe.

35 Véase A. Brown, "Savonarola, Machiavelli and Moses: A Changing Model", en A. Brown, The Medici in Florence: The Exercise and Language of Power, Florencia, Olschki, 1992, pp. 263-79, especialmente 264.

36 Discursos, III, xxx, 18-19, ed. cit., p. 383 .

37 Discursos, III, xxx, 20, ed. cit., p. 383

38 Nos referimos a la famosa carta a Ricciardo Becchi, embajador florentino en Roma, de 9 de marzo de 1498 , recogida en Maquiavelo, Antología, pp. 43-47; sobre esta carta, véase Sasso, Niccolò Machiavelli (1993), op. cit., pp. 25-40; sobre la evaluación posterior del fraile, véase Martelli, Tra filologia e storia, cit., pp. 23977; aporta sugerentes consideraciones, aunque no siempre sólidamente fundamentadas, M. Vatter, "Politica plebea e provvidenza in Machiavelli", en R. Caporali-V. Morfino-S. Visentin (eds.), Machiavelli: Tempo e conflitto, Milán, Mimesis, 2012, pp. 219-240 (versión inglesa, algo ampliada, "Machiavelli and the Republican Conception of Providence", The Review of Politics, 75, 2013, pp. 605-623. Nos referiremos siempre a esta última versión).

39 Discursos, III, xxx, 21, ed. cit., p. 383; todos los errores de juicio indicados por Maquiavelo encuentran censura inmisericorde en El Príncipe: el error de fiarse al beneficio del tiempo en cap. III (pp. 39 ss.); la insuficiencia de la bondad en cap. XV (p. 83: “el hombre que quiera hacer en todos los puntos profesión de bueno labrará 
El juicio sobre Soderini se encuentra repetido y ampliado con un mayor análisis y despliegue de razones en Discorsi, III, iii. Todo él merecería ser citado por entero; sin embargo nos limitaremos a registrar un punto importante. Maquiavelo reconoce que la política de Soderini estaba determinada porque "pensaba (y muchas veces lo confirmó con sus amigos $)^{40}$ que si quería hacer frente valientemente a su oposición y derrocar a sus adversarios [los optimates envidiosos], le sería necesario hacerse con una autoridad extraordinaria y romper con las leyes la igualdad civil"41. En suma, hubiera tenido que pasar de un principado civil a un ejercicio absoluto de la autoridad (como dice en El Príncipe, IX) o en otras palabras: haber ejercido contra los envidiosos del nuevo orden la violencia que la Biblia atribuye a Moisés. Maquiavelo constata y hasta cierto punto aprueba los escrúpulos de Soderini: "Y esta autoridad, aunque de momento no fuese usada por él de forma tiránica, causaría tanta afrenta a los ciudadanos de Florencia, que, cuando él hubiese muerto, ya nunca querrían nombrar un gonfaloniero vitalicio, institución que consideraba necesario continuar y mantener".

"Este recelo era sabio y bueno", continúa Maquiavelo, "pero sin embargo nunca se debe dejar que un mal progrese por respeto a un bien, cuando aquel bien puede ser fácilmente aniquilado por ese mal"'42. El antiguo secretario afirma que Soderini hubiera podido (y debido) actuar como Moisés, tanto más cuanto que, "habiéndose de juzgar sus obras e intenciones por el $\mathrm{fin}^{43}$ (si la fortuna y la vida le hubieran acompañado [es decir, si hubiera podido y sabido ejecutar su política violenta]) podía demostrar a todos que lo que había hecho era por la salvación de la patria y no por su propia ambición" 44 , en suma que era buono, además de savio e potente cittadino ${ }^{45}$. Soderini, por tanto, se equivocó cuando, a diferencia de Savonarola, estaba en sus manos haber imitado a Moisés.

\section{Conclusión}

Moisés vuelve a aparecer en El Príncipe, como no podía ser de otra manera, en el capítulo conclusivo, en la "Exhortación a ponerse al frente de Italia y liberarla de los bárbaros". En este ejercicio retórico, construido en paralelo a la presentación de la figura del príncipe "completamente nuevo" en el capítulo VI, Moisés reaparece junto

necesariamente su ruina entre tantos que no lo son"); la variabilidad de la fortuna en caps. XXIV-XXV y la imposibilidad de aplacar el mal con beneficios en cap. VII ("quien cree que nuevas recompensas hacen olvidar a los grandes hombres las viejas injusticias, se engaña”). Véase Fournel-Zancarini, art. cit., pp. 54-55, 59 y sobre la opuesta valoración de Savonarola y Soderini Martelli, Tra filologia e storia, op. cit., pp. 247, 249-250.

40 Maquiavelo, por su carácter de estrecho colaborador y ejecutor de la política de Soderini, debía ser uno de ellos.

41 Discursos, III, iii, 8, ed. cit., p. 298.

42 Discursos, III, iii, 8, ed. cit., p. 298, cursiva nuestra.

43 Tengamos presente que, según El Príncipe XVIII, ed. cit., p. 92, "en las acciones de todos los hombres y especialmente de los príncipes, donde no hay tribunal al que recurrir, se atiende al fin. Trate, pues, un príncipe de vencer y conservar su estado, y los medios siempre serán juzgados honrosos y ensalzados por todos, pues el vulgo se deja seducir por las apariencias y por el resultado final de las cosas, y en el mundo no hay más que vulgo"; cfr. Discorsi, I, ix, 6-7: "un ingenio sabio no reprenderá jamás a quien se sirviera de alguna acción extraordinaria para ordenar un reino o constituir una república. Lo natural es que si lo hecho le acusa, el resultado lo excuse, y cuando el resultado es bueno [...], siempre le excusará, porque se debe reprender a quien usa de la violencia para destruir, no a quien la usa para recomponer" (ed. cit., p. 57; traducción modificada).

44 Discursos, III, iii, 11, ed. cit., p. 298.

45 Cfr. las cualidades del buen legislador establecidas en Istorie fiorentine, IV, 1. 
con Ciro y Teseo. No lo hace como modelo a imitar por la variante del príncipe nuevo que es el príncipe civil del capítulo IX, de acuerdo con esa referencia florentina que, implícita en ese capítulo (clamorosamente carente de ejemplos "frescos", que sin embargo el destinatario Giuliano sabrá poner por sí mismo), se hace explícita, como hemos visto, en Discorsi III, xxx y iii. Lo hace como figura que actúa sobre una nación, Italia, para quien la fortuna (presentada como abiertamente favorable) ${ }^{46}$ lo destina como "redentor": "Era necesario para ver la virtud de Moisés que el pueblo de Israel estuviera esclavo en Egipto, [...] era necesario para conocer la virtud de un espíritu italiano que Italia se viera reducida a la condición en que se encuentra ahora: más esclava que los hebreos" ${ }^{47}$. Maquiavelo amplía la tradicional identificación de Florencia con Israel, identificación clamorosamente exacerbada en la predicación savonaroliana ${ }^{48}$, a Italia y apela a "la ilustre casa vuestra" (repetida cinco veces en este capítulo conclusivo), a los Médici a asumir el papel de "redentor" (dos veces) de Italia, pero donde el arquetipo del redentor no es Cristo (cuyo reino no es de este mundo), sino Moisés, fundador de un corpus politicum ${ }^{49}$. La apelación iba dirigida tanto al papa Médici Leon X, verdadero señor de Florencia, como al segundo dedicatario de El Príncipe, su sobrino Lorenzo de Médici, a quien se dirigió la obra tras la muerte en 1516 del primer dedicatario, Giuliano (hermano del pontífice). Ya el 12 de julio de 1513 Francesco Vettori había informado a Maquiavelo de las intenciones del recién elegido León X de "conservar a la Iglesia en la reputación en que la ha encontrado, no querer que su Estado disminuya, a no ser que la posible disminución la concediera a los suyos, es decir, a Giuliano y a Lorenzo, a quienes piensa dar Estados por el procedimiento que sea". La noticia, muy divulgada e interpretada en el sentido de hacer a Giuliano príncipe de un estado nuevo en la Italia central y a asentar a Lorenzo en Florencia, impulsó sin duda a Maquiavelo a la redacción de El príncipe como vía, además, para ofrecerse a los Médici, por la mediación de Vettori, como consejero

46 El paralelismo con Moisés se hace patente en la retórica equiparación del momento presente con el éxodo bíblico: "Se ven aquí hechos extraordinarios sin parangón realizados por Dios mismo: el mar se ha abierto [Éxodo 14,21], una nube os ha mostrado el camino [Éxodo 13, 21], ha manado agua de la roca [Éxodo 17, 6], ha llovido aquí maná [Éxodo 16, 5]", El Príncipe, XXVI, ed. cit., p. 121). Significativamente, y en ello se muestra en nuestra opinión el error metodológico de De Grazia, op. cit., pp. 66 s., como si de hechos verificados en el momento contemporáneo se tratara, no percatándose del componente retórico existente en el discurso de Maquiavelo acerca de Moisés.

47 Ed. cit., p. 120.

48 Véase Geerken, art. cit., p. 588; el motivo ya había sido señalado en F. Gilbert, "Le idee politiche a Firenze al tempo di Savonarola e Machiavelli", en F. Gilbert, Machiavelli e il suo tempo, Bolonia, Il mulino, 1964, pp. 101 ss.; con posterioridad ha sido objeto de estudio en profundidad en D. Weinstein, Savonarola and Florence: Prophecy and Patriotism in the Renaissance, Princeton, Princeton University Press, 1970, y en D. Polizzotto, Savonarola and Florence: Prophecy and Patriotism in the Renaissance, Princeton, Princeton University Press, 1994; ha ofrecido recientemente muy sugerentes consideraciones en Vatter, art. cit., p. 226 ss.

49 Nos alejamos en este punto de la interpretación de Vatter, para quien la figura del "redentor" no remite al profeta Moisés, sino al Mesías (como rey escatológico de Israel), por la cual razón Moisés no estaría en realidad contemplado en el capítulo XXVI de El príncipe: véase Vatter, art. cit., pp. 618 ss; creemos, por el contrario, que Maquiavelo no usa en estricto sentido teológico (cristiano) o en sentido teológico-político (hebreo) el concepto de "redentor", sino en sentido puramente político y retórico, para referirse al príncipe nuevo que Italia necesita y del que Moisés es el arquetipo. Si no fuera así, no vemos qué sentido pueden tener las menciones explícitas de Moisés y las alusiones al Éxodo en este capítulo. En nuestra opinión Vatter supone un paralelismo excesivo entre Maquiavelo y las especulaciones hebreas sobre la liberacón de Israel, atribuyendo al secretario fiorentino una información muy vasta sobre el pensamento hebreo para la cual no aduce pruebas suficientes; en cambio, infravalora la aportación de la tradición averroísta, leída en clave rigorosamente política, a la lectura decididamente política de Moisés por parte de Maquiavelo. 
político y recuperar la posición y dignidad perdidas ${ }^{50}$. Estas circunstancias explican sin duda la atención prestada al principado civil (y el silencio sobre Piero Soderini) y también la mirada más nacional, que tras la muerte de Giuliano en marzo de 1516 se focalizó exclusivamente en Lorenz ${ }^{51}$.

Moisés aparece, pues, en el capítulo exhortativo final como modelo a imitar por Lorenzo de Médici, no tanto como príncipe civil de Florencia a quien se propone una alianza histórica con el pueblo frente a los optimates siempre "envidiosos", sino como "redentor" de Italia, a quien por otra parte se dice que ninguna envidia se le opondría ${ }^{52}$. El paralelismo con Moisés aparece ahora plausible, puesto que el capítulo final atribuye a la casa Médici una política militar basada en la enseñanza de Maquiavelo (empleo de armas propias) y por tanto hace del principe mediceo un "profeta armado" frente al desarmado Savonarola ${ }^{53}$.

La autoidentificación de Savonarola con Moisés ha sido frecuentemente señala$\mathrm{da}^{54}$. En el momento peligroso de 1498, el fraile desarrolló una serie de sermones sobre el Éxodo bíblico. A dos de ellos al menos, pronunciados el 2 y 3 de marzo asistió Maquiavelo, quien dio cuenta de ellos en la carta ya mencionada a Ricciardo Becchi. En un momento determinado Maquiavelo dice: "llegando a aquel sitio donde se dice que Moisés mató a un egipcio, dijo que el egipcio eran los hombres malos y Moisés el predicador que los mataba descubriendo sus vicios. Y dijo. «Egipcio, te doy a dar una cuchillada»" ${ }_{55}$. Para Savonarola, pues, la "cuchillada" y el "homicidio" no pasan de ser metáforas de una denuncia verbal. La razón, como ya hemos visto, es que Savonarola no podía ir más allá, por su condición eclesiástica y por no haber podido mover en la dirección necesaria a sus seguidores. Por eso, es un falso Moisés y Maquiavelo dice en el capítulo XII de El Príncipe, cuando ha expuesto ya su teoría de las "armas propias", en clara alusión a Savonarola: "quien decía que la causa de todo ello [la invasión de Carlos VIII de Francia en 1494] se hallaba en nuestros pecados, tenía razón, sólo que no eran los que él creía, sino los que yo acabo de exponer"56. Para Maquiavelo, Savonarola está ofuscado por la perspectiva errónea cristiana de la finalidad ultramundana y trascendente del hombre, que le lleva a la interpretación espiritualista de los "pecados" y de la "redención". Sugerentemente, Vatter ha señalado que, en consonancia con el protagonismo exclusivamente divino del providen-

$50 \quad$ Véase Bausi, Machiavelli, op. cit., pp. 200-16.

51 La cuestión se conecta con el problema, en el que no podemos entrar aquí, de la cronología de la redacción del capítulo XXVI: o modificación en 1516 para adaptarlo a las nuevas cirunstancias (Sasso, Inglese), o finalización en 1518 en la cronología amplia que para El príncipe postulan Martelli y Bausi.

52 El Príncipe, XXVI, ed. cit., p. 123: “QQué pueblos le negarían la obediencia? ¿Qué envidia se le opondría?”. Según Vatter 2013: 618 ss., la razón por la que ninguna envidia se le opondría es que el pueblo italiano ahora ni está desarmado ni es esclavo, como Israel en Egipto. En ello se basa el estudioso chileno para afirmar que el "redentor" de Italia no está modelado sobre la figura de Moisés, ni puede ser un nuevo Moisés. A las razones que ya hemos dado en contra (cf. nota 50), podemos añadir que Maquiavelo puede afirmar (con buena dosis de retórica) que «ninguna envidia se le opondría» al nuevo Moisés porque la envidia es una pasión de los grandes y, como ha dicho El príncipe en el cap. XVIII, los grandes, "los pocos no tienen sitio cuando la mayoría tiene donde apoyarse" (cf. nota 24).

53 Para un ulterior eco de esta concepción maquiaveliana de Moisés en el óleo de Rosso Fiorentino representando a "Moisés defendiendo a las hijas de Jetro" (Uffizi, ca. 1523), véase V. Gaston,"The Prophet Armed: Machiavelli, Savonarola, and Rosso Fiorentino's Moses defending the Daughters of Jethro", Journal of the Warburg and Courtauld Institutes, 51, 1998, pp. 220-223; a Rosso Fiorentino se atribuye también un retrato de Maquiavelo, ahora en paradero desconocido.

54 Geerken, art. cit., p. 587; Brown, art. cit., pp. 269 ss.

55 Antología, op. cit., p. 45 ss.

56 Ed. cit., p. 72. 
cialismo cristiano, el profeta (y por tanto Savonarola) "can only be unarmed", ya que en la lógica cristiana de la providencia "God's plan will be realized in history, and at the same time $[\ldots]$ human beings cannot make their history"57. Pero hay que tener presente que esta historia, la única que cuenta en verdad para el cristianismo y de la que Dios es el agente, es la historia espiritual de la redención, cuya finalidad es trascendente. Por el contrario, Maquiavelo, según Vatter, "is breaking with Christian economical Providence. Instead he joins together a Jewish understanding of divine Providence (an under standing for which, ironically, Savonarola's preaching [con sus contradicciones, podemos añadir nosotros] had amply prepared the terrain) with a neo-Roman vocabulary of virtus as locked in struggle against fortune" ${ }^{\prime 58}$. De ahí la lectura puramente política que Maquiavelo hace de los "pecados" y la reducción política del programa de "redención" 59 , que le permite ver la acción del príncipe nuevo y profeta armado, de acuerdo con la concepción hebraica de la providencia, según la cual "God is present in history as the military leader of his Chosen People, leading them in their wars against other nations to regain their «promised land», which is a land on earth and not in a supernatural beyond" ${ }^{60}$. En suma, Maquiavelo habría asumido tácitamente la concepción mundana del reino de Dios. Es verdad, sin duda, que en el imaginario impuesto a los hebreos por Moisés el comandante del pueblo que lo guía en la empresa político-militar es Dios mismo (como en el caso de la Florencia republicana que, siguiendo a Savonarola, había hecho a Cristo rey de la ciudad) ${ }^{61}$, pero pocas dudas caben de que para Maquiavelo esa es una persuasión infundida en el pueblo por el profeta Moisés, el cual (según el secretario florentino) nunca puede creerse el mito que impone al colectivo.

Resulta, pues, que Savonarola no podía ser de ningún modo, a los ojos de Maquiavelo, un nuevo Moisés, el profeta que necesita Florencia e Italia. ¿Podríamos decir, como ha sostenido Leo Strauss, que Maquiavelo piensa que él mismo es Moisés? ${ }^{62}$. Esto último es obviamente una exageración, como el mismo Strauss reconoce cuando califica a Maquiavelo de profeta desarmado ${ }^{63}$ y cuando parece desplazar el problema de la efectiva acción política de renovación y "redención" llevada a cabo por el necesario Moisés nuevo al de la revelación de "un nuevo código, de un nuevo decálogo. [...] El portador del nuevo código o Tablas de la ley (de la legalidad de la acción política) no es otro que el mismo Maquiavelo: él trae el código que lo

\footnotetext{
Art. cit., pp. $611 \mathrm{ss}$
}

Ibidem, p. 612.

59 En este sentido podemos decir que Maquiavelo anticipa la mundanización (más que secularización, porque se asocian en todo caso a una divinización de la naturaleza) de los conceptos centrales de la teología llevada a cabo por Giordano Bruno (en la Expulsión de la bestia triunfante) y por Spinoza (en el Tratado teológico-político y la Ética): véase M. Á. Granada, "Cosmología y polémica religiosa en los escritos de 1588 (materiales para una aproximación de Bruno y Spinoza en el ámbito de la teología política», en M- Á Granada, Giordano Bruno: universo infinito, unión con Dios, perfección del hombre, Barcelona, Herder, 2002, pp. 127-67.

60 Ibidem, pp. 613 ss.

${ }^{61}$ Ibidem, p. 612. El pasaje aparece más desarrollado en la versión italiana; véase Vatter 2012: 226-228. Muy oportunamente Vatter cita un pasaje del ciclo de Sermones sobre Ageo pronunciados por Savonarola a finales de 1494, en el momento decisivo de la determinación de la nueva constitución de la República florentina: "Orsù, Firenze, che vorresti tu, che capo, che re ti si può dare, che tu stia quieta? [...] Orsu Firenze, Iddio ti vuol contentare e darti uno capo ed uno re che ti governi. E questo è Cristo [...] Cristo sia tuo capitano", ibidem, pp. 226 ss.

62 Véase L. Strauss, Meditación sobre Maquiavelo, Madrid, Instituto de Estudios Políticos, 1964 1964, p. $98:$ "No Lorenzo, sino Maquiavelo, es el nuevo Rómulo-Numa o el nuevo Moisés".

63 Ibidem, pp. 200 ss. 
es realmente, el código que está en consonancia con la verdad, con la naturaleza de las cosas" "64. Pero con ello Strauss, en su crítica de la modernidad y de la Ilustración como ruptura con la Gran Tradición de la filosofía política clásica, por tanto como "Ofuscación" ${ }^{65}$, desplaza el problema de la acción política a realizar (el problema de Maquiavelo) a la teoría de la política que, fundada por Maquiavelo como inspiradora de la "redención" de Italia, abre por otra parte la modernidad. En los términos en que Maquiavelo veía el problema, no podía en modo alguno verse a sí mismo como el nuevo Moisés que Florencia e Italia necesitaban. Pero sí, ciertamente, podía verse como el más experimentado, lúcido y leal consejero que el nuevo Moisés podía (incluso debería) tener a su lado en la tarea histórica que le incumbía. En conclusión: los Médici harían muy bien en

comenzar por hacerme dar vueltas a una piedra, porque si después yo no me los ganaba me compadecería de mí mismo. Por eso, si se leyera mi obra, se vería que los quince años que he pasado entregado al arte del Estado no los he ni dormido ni jugado, y todo el mundo debería valorar el servirse de alguien cargado de experiencia a cuenta de otros. De mi lealtad no debería haber duda alguna, porque habiendo observado siempre la palabra no voy ahora a aprender a romperla, y quien se ha mantenido fiel y bueno durante cuarenta y tres años, que son los que yo tengo, no debe poder cambiar de naturaleza; y de la lealtad y bondad mía testimonia mi pobreza ${ }^{66}$. 